\title{
O vazio político do realismo contemporâneo, ou da anarquia que vem
}

\section{The political void of contemporary realism, or the anarchy that comes}

DOI: $10.20873 / r p v 6 n 2-25$

\author{
Catherine Malabou \\ Orcid: https://orcid.org/0000-0002-2971-4707 \\ E-mail: c.malabou@kingston.ac.uk \\ Tradução e apresentação \\ Antonio Frank Jardilino Maciel* \\ Orcid: 0000-0001-7607-1823 \\ Email: Antonio_Franck.Jardilino_Maciel@paris-sorbonne.fr
}

\section{Breve introdução ao pensamento de Catherine Malabou}

A obra de Catherine Malabou tem atraído atenção no debate filosófico internacional graças às suas reflexões em torno do conceito da plasticidade, que no contexto científico se tornou uma das noções mais significativas dos últimos tempos. Deslocada de seu contexto original, a estética, a plasticidade continua a revelar o seu potencial filosófico, científico e epistemológico. Este alargamento a diferentes campos do saber nos obriga a indagar a natureza metamórfica, diferencial e transformacional da plasticidade. Dotada de um triplo sentido, a palavra

\footnotetext{
* Especialista clínico-musical na reabilitação cognitiva e psicomotora (2006), doutorado em Disciplinas Musicais (2011), Mestre em ciências filosóficas (2017), atualmente é doutorando e membro do grupo de pesquisa da LCI (Equipe de Literatura et Cultura italiana) da Sorbonne Université e do Departamento di ciências filosóficas da Università degli studi Università degli Studi Chieti-Pescara "G. d'Annunzio". Tem desenvolvido estudos aplicados que evolvem filosofia, literatura, artes, neurociências e neurobiologia.
} 
plasticidade se refere seja à capacidade de receber e dar forma, como à sua explosão (plasticage, explosivo plástico). Em outros termos, a plasticidade desvela a aventura da forma. Em seu primeiro livro (como em outros trabalhos), L'avenir de Hegel: plasticité, temporalité, dialectique [0 advir de Hegel: plasticidade, temporalidade, dialética], tese de doutoramento supervisionada por Jacques Derrida e publicada em 1996, Malabou articula de forma magistral questões fundamentais do pensamento filosófico. Pela primeira vez, com Hegel, a plasticidade será concebida e relacionada à essência, a qual é descolada de sua ancoragem estritamente estética e situada em um campo realmente problemático que, até então, nunca fora seu especificamente: o da subjetividade. 0 sujeito, de agora em diante, será considerado plástico e não como instância fixa, sólida e substancial. Em outras palavras, os significados fundamentais da plasticidade - a recepção e a doação da forma - serão, de fato, investidos de um valor radicalmente novo, designando a capacidade do sujeito de se formar e de se transformar; de metamorfosear inteiramente a própria forma; ou ainda, de explodi-la e, consequentemente, de fabricar um novo substituto. Como demostra Malabou, Hegel é um dos primeiros a ressaltar que toda nova forma, ao surgir, provoca o desaparecimento de uma outra mais antiga, ou seja, que a nova forma emerge como possibilidade de sua própria autodestruição. A plasticidade, portanto, caracteriza o espaço mais sensível e dinâmico, o verdadeiro coração pulsante da subjetividade, o espaço de sua relação com o advir, com o evento, com tudo aquilo que lhe acontece e resta, assim, aberto a todo tipo de alteridade. Com essa forma de abordagem, entra-se, de fato, não somente em uma era desconstrutiva, mas pós-desconstrutiva que concerne justamente à subjetividade.

A partir desses pressupostos, não somente se recupera o conceito de subjetividade, em crise durante toda a modernidade e a pós-modernidade, mas o sujeito passa por um processo de dessubstancialização e esvaziamento. Porém, o caminho da plasticidade não termina com Hegel. Depois, em uma tentativa de reaproximação entre filosofia e ciência, a autora encontra nas neurociências e na neurobiologia a possibilidade de pensar um novo "esquema-motor" para a filosofia em que predomina precisamente a plasticidade da forma. Nesse caso, o cérebro, a "cerebralidade" ocupa um espaço que funciona como modelo de uma ontologia dinâmica. A plasticidade, desta vez, se refere especificamente à capacidade das sinapses de modificar sua eficiência de transmissão. As sinapses, de fato, não são fixas; não são meros transmissores de 
informações nervosas, mas possuem o poder de formar ou de reformar essas mesmas informações. Eis que se torna claro o objetivo de garantir o fundamento para a construção de um "novo materialismo". Não é possível definir a plasticidade sem redesenhar esse tipo de abordagem que interroga a relação ou o conjunto de relações definidas entre a matéria (cérebro) e a mente, entre o biológico e o simbólico. Desde Que faire de notre cerveau? [Que fazer do nosso cérebro?] (2004), as correntes que separam o biológico do simbólico serão permanentemente colocadas em discussão, justamente problematizando a possibilidade da eliminação deste gap, à medida que a biológico foi sempre a parte mais transcurada desse entre-deux. Como afirma a autora: a vida biológica é capaz de criar, de produzir sua própria simbolização. Em Ontologia do acidente (2009), Malabou explora precisamente a dimensão explosiva, definindo o contorno da plasticidade destrutiva. Essa obra, na verdade, funciona em estreita conexão com Les nouveaux blessés: de Freud à la neurologie, penser les traumatismes contemporains [Os novos feridos: de Freud à neurologia, pensar os traumatismos contemporâneos], na qual a autora desenvolve uma crítica à teoria freudiana da indestrutibilidade da psique e à teoria da anterioridade do trauma. 0 fio condutor dessas duas obras é que a destruição da estrutura biológica corresponde à destruição da estrutura simbólica. 0 limite entre estes dois componentes parece, assim, aproximar-se. Outro objetivo de fundamental importância é desconstruir a compreensão da biologia ligada à ideia de soberania, como se a biologia fosse um tipo qualquer de poder (biopoder) ou fornecesse a justificativa de um determinado paradigma de poder (biopolítica). O que as ciências da vida nos oferecem é um quadro completamente transformado e a filosofia não pode mais ignorar a dimensão dessa revolução. Nisto há uma enorme recaída no campo da subjetividade. Certamente, o sujeito não pode mais ser designado como uma instância pré-constituída, pré-determinada ou uma entidade substancial. Em suma, em Avant demain, a autora questiona o caráter transcendental do pensamento e sua materialidade. A noção de epigênese, nesse caso, afirmase como uma "nova forma de transcendental". É a partir desse quadro teórico que o artigo aqui traduzido dever ser interpretado: entre a sua materialidade e exigência de pensar novas formas de subjetividade. Afinal, já começou a reviravolta anárquica do sujeito? 


\section{O vazio político do realismo contemporâneo, ou da anarquia que virá*}

\section{Catherine Malabou}

"O vazio político do realismo contemporâneo": essa fórmula tem dois significados contraditórios. Por um lado, ela sublinha a ausência de uma dimensão política do realismo contemporâneo. Nesse sentido, a fórmula é uma ofensiva. Mas, por outro lado, a mesma designa um espaço: o "vazio político" aprece então como um lugar. Seria preciso dizer: "o vazio como lugar político", o título ressoaria assim como uma promessa. 0 realismo contemporâneo conteria a semente de uma nova visão do político.

Eu sintetizaria as duas compreensões da fórmula afirmando que o realismo contemporâneo é rico de desafios políticos que, ao mesmo tempo, estranhamente, ele não tematiza. É desta forma que os "realistas" nunca questionam o eco subjetivo do adeus que eles dão ao sujeito. Não veem as consequências, para os sujeitos, de uma definição de um real sem sujeito. Na medida em que o conceito de "processo sem sujeito" tem sido uma pedra de toque do marxismo contemporâneo, - particularmente do pensamento de Althusser -, parece importante confrontar hoje realismo e materialismo acerca do sentido político do vazio do sujeito. 0 que resta do sujeito quando o real se esvaziou? Podemos pensar em um sujeito residual? Um sujeito que seria, então, retomando a bela ideia dos coordenadores deste volume, o eco do real. Esse eco é simplesmente uma forma ao mesmo tempo transformada e prolongada do marxismo ou anuncia um outro devir?

Permitam-me antes de mais nada esclarecer o sentido e a relevância daquilo que nomeei de forma precipitada como "realismo" e que, evidentemente, é apenas o momento

\footnotetext{
*C. MALABOU, “Le vide politique du réalisme contemporain, ou de l'anarchie qui vient”. In: L'écho du réel. Ed, C. Crignon, W. Laforge, P. Nadrigny, Sesto Sagiovanni. Milano: Mimesis, 2021.

0 tradutor e a Revista Perspectivas agradecem à autora pela autorização para publicar esta tradução.
} 
contemporâneo de uma tradição antiga e plural. Os "realistas" dos quais estou falando são os filósofos que se reagrupam, pelo menos por um determinado tempo, sob a bandeira do "realismo especulativo". Na época em que escrevi este texto, ocorreram algumas rupturas entre esses pensadores. Todavia, mesmo renunciando a ver no surgimento do realismo especulativo, em meados dos anos 2005, a constituição de um movimento unitário, considero possível identificar pontos de convergência entre os caminhos singulares que o constituem.

Todos os "novos realistas" insistem, por exemplo - e que exemplo! -, no fato de que o realismo não é um materialismo. Em uma entrevista publicada no jornal canadense Chiasma1, Graham Harman faz questão de justificar essa distinção. “0” ou "os" realismos contemporâneos não são assimiláveis nem ao materialismo do século XVIII, nem ao materialismo dialético, nem, enfim, ao que hoje chamamos os "novos materialismos". Que seriam, portanto, segundo Harman (2018, p. 82), movimentos "furiosamente antirrealistas (mostly rabid anti-realist mouvements)". Sem poder entrar na difícil questão das relações entre realismo e materialismo na tradição filosófica, eu, ainda uma vez, parto simplesmente do aspecto mais contemporâneo dessas relações. Penso me pronunciar contra a afirmação de Harman e defender que o materialismo, longe de ser um antirrealismo, compreende o realismo, ou seja, ao mesmo tempo o contém e entende suas questões com mais lucidez do que ele mesmo. Como se o materialismo designasse também a relação dialética que o realismo mantém com seus próprios silêncios. Até mesmo com suas próprias denegações. Uma análise materialista do realismo especulativo permitiria, portanto, construir o diálogo entre o realismo e aquilo que o mesmo eclipsa ou oculta, isto é, precisamente a questão política. Esta análise é logo dispensada devido ao tratamento particularíssimo que o realismo dá ao conceito de sujeito.

"Os" realistas especulativos unanimemente denunciam, como sabemos - eis aqui um segundo ponto essencial de convergência -, o "correlacionismo". De acordo com Meillassoux (2004, p. 16), um "correlacionismo" do qual o materialismo ainda seria tributário, na medida em que continua a partir da "relação de um sujeito com o mundo". Porém, quando o realista afirma que o real só existe de-correlacionado, o materialista pergunta: o que acontece com o

\footnotetext{
${ }^{1}$ G. Harman, "The Future of Continental Realism. Heidegger's Fourfold". In Chiasma Issue 3, 28 de outubro 2018, pp. 81-98.
} 
sujeito depois de dispensado? Ele pura e simplesmente desaparece do palco do real? Ou será para retomar um termo de Jacques-Alain Miller - apenas "suturado" (MILLER, 1966, p. 37-49)? Excluído, mas ainda visível em sua ruptura?

A posição materialista que defendo é a de um materialismo "pós-realista", que assinala os efeitos do eclipse brutal do sujeito questionando a natureza e o destino do vazio que a decorrelação deixa para trás. Para o materialista, todo vazio é uma promessa de forma, isto é, antes de tudo a materialização de uma ausência. É a materialização do eclipse do sujeito, como o lugar da questão política, que hoje é preciso pensar.

\section{Harman e o direito próprio das coisas}

Em primeiro lugar, prossigamos brevemente com a exploração da rejeição realista do materialismo, mostrando rapidamente suas articulações fundamentais.

Antes de mais nada, retornemos a Harman. No artigo intitulado The Four Most Typical Obejctions to 000 ("As quatro objeções mais comuns contra a 000"), ele salienta as linhas principais da agora famosa "Object Oriented Ontology" ("Ontologia Orientada aos Objetos"). Tratase de afirmar que as coisas habitam um espaço fora do sujeito, que se recusa a todo acesso. A originalidade de Harman consiste em encontrar em Heidegger os meios de uma abordagem "realista" às coisas: a "coisa" é de fato "uma coisa" apenas em seu "retraimento". "0 princípio básico da filosofia orientada aos objetos, que eu faço derivar da análise heideggeriana da ferramenta, é que os objetos se retiram de todo contato, tanto teórico quanto prático" (HARMAN, 2013, p. 32). Esse retraimento manifesta, negativa e paradoxalmente, um excesso. 0 excesso do real sobre o pensamento.

"O que fazem as coisas em si, umas com as outras, quando os humanos não as estão olhando? - pergunta ainda Harman. Não haveria relação entre as coisas fora de nós?"2 Nenhum filósofo parece ter levado esta questão realmente a sério. A própria ciência de qualquer forma a contornou. Para o cientista, de fato, "uma bola de bilhar bate numa outra, um pedaço de ferro

\footnotetext{
2 "What do the things in themselves do to each other when humans are not looking? Are there really no relations between these things apart from us?" (HARMAN, 2018, p. 92).
} 
é atraído por um ímã etc." (HARMAN, 2013, p. 34). Os objetos não têm nenhuma consistência além do número limitado de relações que permitem que os mesmos sejam pensados. Ora, precisamente, o real não se reduz a determinações do pensamento. As relações causais não exaurem de forma alguma as relações que as coisas mantêm entre si, relações das quais "nós" nada sabemos. As coisas existem "por direito próprio (in their own right)" (HARMAN, 2013, p. 34).

Mas o materialismo seria apenas uma "redução" suplementar desse direito das coisas [de existir]. Não faria, de fato, nada além de "decompor" a matéria (HARMAN, 2013, p. 34). Átomos ou quanta, pouco importa.

\section{Brassier: a matéria sem conceito}

Por essa razão, pode-se objetar que o materialismo também afirma o primado do real sobre as determinações do pensamento!

Ray Brassier (2001) responde precisamente que essa objeção não tem nenhum fundamento. Desde o início, em sua tese Alien Theory: The Decline of Materialism in the Name of Matter, ele se propõe a identificar os fundamentos do "não-materialismo", um conceito moldado sobre aquele da "não-filosofia" proposto por François Laruelle. 0 "não-materialismo" não é um simples "antimaterialismo", mas um empreendimento que tende a libertar o materialismo de seu idealismo implícito. De fato, segundo Brassier, a decisão materialista que consiste em assimilar o real à matéria deriva de uma confusão entre matéria e conceito. A "matéria" permanece um "conceito" de matéria, portanto, uma categoria. Trata-se - para o não-materialismo, isto é, o realismo - de elaborar precisamente uma teoria da "matéria sem conceito" (BRASSIER, 2001, p. 139). Em The Unchained Nothingness: Lights and Extinction, essa posição se mostra mais precisa (BRASSIER, 2017). "O objeto se torna, a uma só vez, paciente e agente de sua própria determinação cognitiva". Referindo-se à noção de "determinação-em-última-instância”, proposta por François Laruelle, Brassier afirma novamente:

[...] Ao invés de invocar não se sabe qual harmonia pré-estabelecida entre o ser e o pensamento, a determinação-em-última-instância desfaz a síntese correlacional a fim de efetuar (ao invés de representar) uma identidade sem unidade ou dualidade, sem a distinção sujeito-objeto. A mesma efetua uma disjunção não correlacional entre uma realidade não objetifivável e uma objetivação ideal por 
meio da identidade-em-última-instância entre o ser-excluído do objeto e aquele do real enquanto nada. (BRASSIER, 2017, p. 139. Tradução modificada [C.M.])

De certa forma, trata-se, então, de "desobjetificar" o conceito de matéria, já que a noção de "objeto" é justamente um resíduo conceitual que separa a matéria do real. 0 que Brassier chama de "niilismo" deriva do reconhecimento do espaço ínfimo que separa a resistência da realidade do nada. Na verdade, põe-se a questão de saber se, "em última instância", um real que se nega não é, simplesmente, um nada. Como não recordar aqui que as palavras "real" e "nada" têm a mesma origem: res, a coisa? Mas esse nada, esse vazio material do real é precisamente o que resiste a qualquer abordagem subjetiva, incluindo aí a abordagem dialética.

Brassier, por sua vez, desenvolve uma crítica da representação científica do real como um conjunto de objetos. "A representação científica parte do princípio de que algo no próprio objeto determina a discrepância entre sua realidade material - o fato que ele mesmo seja, a sua existência - e seu ser, determinado como quididade - não somente que é, mas tudo o que é" (BRASSIER, 2011, p. 55). Essa discrepância entre ser e tal ser coincide com a distinção tradicional entre objeto e realidade. 0 problema é que essas distinções são operadas no conceito, nunca no real. Não há diferença no real. Portanto, qualquer abordagem dialética do real está destinada a permanecer prisioneira do idealismo da diferença. 0 materialismo dialético, articulado em torno de contradições, negações, cisões, avatares da diferença, não escapa desse cativeiro.

Meillassoux: O materialismo quando é "especulativo" termina em realismo

A linha divisória entre realismo e materialismo parece, à primeira vista, menos rígida no livro de Quentin Meillassoux, Après la finitude (Depois da finitude). De fato, Meillassoux começa reconhecendo que os inimigos comuns de todos os correlacionismos, sejam estes quais forem, são o realismo e o materialismo, o que deixa entender que estes últimos são solidários um com o outro e constituem uma linha de frente. A escolha de todo correlacionismo, escreve Meillassoux, 
É a tese da inseparabilidade essencial do conteúdo do pensamento e do ato de pensar. Nós estamos sempre lidando apenas com um-dado-do-pensamento, e não com um ser que subsiste por si mesmo. Esta decisão é suficiente, por si só, para desqualificar todos os absolutos de tipo realista ou materialista. (MEILLASSOUX, 2006, p. 50)

Meillassoux chama "especulativa" todo o tipo de abordagem não-correlacionista do real. Portanto, essencialmente, haveria dois: um materialista e outro realista. À primeira vista, não há diferença entre realismo especulativo e "materialismo especulativo":

De fato, todo materialismo que pretenda ser especulativo - quer dizer, que faria de um certo tipo de entidade sem pensamento uma realidade absoluta - deve consistir em afirmar seja que o pensamento não é necessário (algo pode existir sem o pensamento), seja que o pensamento pode pensar o que deve existir quando não há pensamento. 0 materialismo, se adota a via especulativa, é, portanto, obrigado a acreditar que seja possível pensar uma dada realidade, abstraindo do fato de que a pensamos. 0 mesmo acontece com o epicurismo - paradigma de todo o materialismo - que pretende que o pensamento possa ter acesso, por meio das noções de vazio e de átomo, à natureza absoluta de todas as coisas, pretendendo também que essa natureza não seja necessariamente correlacionada a um ato de pensamento, visto que o pensamento como tal existe somente de forma aleatória, através de compostos atômicos contingentes (até os deuses são divisíveis), ou seja, não-essenciais à existência das naturezas elementares. (MEILLASSOUX, 2006, p. 50)

A proximidade entre materialismo e realismo não resiste por muito tempo à uma análise. Com efeito, esta "contingência" que, para o materialista, caracteriza a "natureza absoluta das coisas" aparentemente livre das relações que "todo ato de pensar" lhe impõe, não é nada. Continua sendo uma necessidade oculta. 0 materialismo erra ao pensar a radicalidade da contingência.

Esta constatação fica mais clara com a distinção entre a contingência e o acaso. 0 movimento dos átomos, em Epicuro, está sujeito ao acaso. No entanto, o acaso ainda supõe, segundo Meillassoux, uma forma de constância física.

Desta maneira, podemos ver claramente em Epicuro que o clinamen, o pequeno desvio aleatório dos átomos, pressupõe a imutabilidade das leis físicas: a forma específica dos átomos (átomos lisos, em forma de gancho etc.), o número de suas espécies, o caráter indivisível dessas pequenas unidades físicas elementares, a existência do vazio etc. - nada disso é modificado pelo próprio clinamen, pois se trata das próprias condições de sua realização (MEILLASSOUX, 2006, p. 136). 
O materialismo, portanto, não nos permite pensar a contingência absoluta das leis da natureza, conceber um mundo desprovido de toda necessidade física, visto que o acaso ainda depende dessa necessidade.

0 pleno direito próprio das coisas, que proíbe a redução do real às determinações do pensamento, supõe a impossibilidade de determinar o real, isto é, de predizê-lo, de sondá-lo, de antecipá-lo. 0 raciocínio aleatório ainda depende de uma totalização prévia das possibilidades. Uma totalização que não resiste a uma abordagem "transfinita" (Cantor). 0 infinito transfinito detona a própria noção de possível. A contingência do real significa a sua modificabilidade absoluta e não uma legislação do possível. 0 real, portanto, deixa de ser uma das possibilidades do real.

0 termo contingência, por outro lado, refere-se ao latim contingere: tocar a, chegar a acontecer, isto é, o que acontece, mas o que acontece o suficiente para que nos toque. 0 contingente existe, em suma, quando algo enfim acontece - uma outra coisa, que, escapando de todas as possibilidades já repertoriadas, põe fim à vaidade de um jogo onde tudo, inclusive o improvável, é previsível. (MEILLASSOUX, 2006, p. 149)

Portanto, algo que "nos" acontece é algo que acontece sem nós. Seja das profundezas da memória não vivida da ancestralidade ou do tempo posterior ao desaparecimento da humanidade.

\section{A resposta de Althusser}

O que responder diante de tudo isso? Há muito tempo, é preciso recordá-lo, que o materialismo saiu do estado de natureza, que já não se preocupa apenas com o movimento dos átomos ou com o problema da necessidade física, mas também com aquele da necessidade política e social, mantendo-as em uma tensa tessitura. Desde Marx, pelo menos, todo materialismo se desdobra 1) no espaço exato da articulação entre as leis da física e as leis da física social, 2) na interseção de dois tipos de legalidade: a natural e a econômica. (Note-se de passagem que a questão das leis da economia não é levada em consideração por nenhum dos "realistas", como se somente as leis da física fossem dignas de interesse). 
Ora, não é difícil ver que a questão da contingência se tornou também a questão central do materialismo contemporâneo, que se situa na intersecção dessas duas legalidades. Uma contingência que justamente não é possível reduzir somente ao "acaso". Afortunadamente, Althusser a caracteriza como "encontro" em seu texto escrito em 1982: A corrente subterrânea do materialismo do encontro (ALTHUSSER, 2005, p. 9-48). De fato, é esse filosofema do encontro que permite, em primeiro lugar, a articulação entre natureza e política e, em segundo lugar, o surgimento de uma nova questão do sujeito compreendido como resíduo do encontro. Althusser esclarece:

a existência de uma tradição materialista quase completamente ignorada na história da filosofia: o "materialismo" (precisa-se mesmo de uma palavra para demarcar a tendência desta tradição) $d a$ chuva, do desvio, do encontro, da pega. Desenvolverei todos estes conceitos. Para simplificar as coisas, digamos por ora: um materialismo do encontro, portanto, do aleatório e da contingência, que se opõe, como pensamento totalmente outro, aos diferentes materialismos recenseados, inclusive o materialismo correntemente atribuído a Marx, Engels e Lenin, o qual, como todo materialismo da tradição racionalista, é um materialismo da necessidade e da teleologia, isto é, uma forma transformada e disfarçada de idealismo. (ALTHUSSER, 2005, p. 9) ${ }^{3}$

Esse materialismo do encontro, ou, diz ainda, "perigoso" (ALTHUSSER, 2005, p. 9), reprimido pelo materialismo oficial, está mais próximo do realismo, na medida em que "começa pelo nada" (ALTHUSSER, 2005, p. 25).

Começar pelo "nada" supõe: 1) precisamente uma dissociação entre começo e conceito de começo, ou "determinação-do-pensamento". 0 materialismo do encontro não pressupõe nenhuma lógica e reivindica "a não-anterioridade do Sentido" ((ALTHUSSER, 2005, p. 10); 2) uma relação de cristalização das coisas entre elas mesmas, a “'pega' dos elementos uns sobre outros (no sentido em que se diz que o cimento 'pega')" (ALTHUSSER, 2005, p. 11); 3) o caráter absoluto da contingência, já que os átomos, inorgânicos ou vivos "pegam forma [prennent forme, tomam forma]"4 fora de qualquer teleologia e sem predição possível. Os indivíduos são como átomos de matéria. Ao se encontrarem, os mesmos se agregam e pegam forma [prennentforme, tomam

\footnotetext{
${ }^{3}$ Nas citações deste texto, os itálicos são os de Althusser [C.M.].

${ }^{4}$ Neste caso específico para manter uma certa coerência terminológica com a tradução brasileira do texto de Althusser, vamos continuar utilizando o verbo "pegar" mesmo que a locução idiomática "tomar forma" seja aquela correta e mais adequada. Sendo assim, toda vez que encontrarmos a mesma locução colocaremos entre colchetes aquela em francês e a forma utilizada em português [N.T.].
} 
forma] sem atualizar nenhum possível, que não preexiste ao encontro. Althusser rejeita a versão do materialismo, há muito predominante, segundo a qual "tudo está consumado de antemão, a estrutura precede seus elementos e os reproduz para reproduzir a estrutura" (ALTHUSSER, 2005, p. 34). Aqui, tudo procede de “um vazio, ontológico e filosófico" (ALTHUSSER, 2005, p. 15). Um vazio que é precisamente o espaço da política.

A abordagem materialista sempre considera a pega [prise, tomada] como uma pega de forma [prise de forme, tomada da forma]. A matéria dos agregados pega forma [prend forme, toma forma] em um espaço vazio, a partir dele, e é essa formação da forma que realiza o necessário advir da contingência - tanto na sua dimensão natural como na sua dimensão histórica.

Ou seja, em lugar de pensar a contingência como modalidade ou exceção da necessidade, é necessário pensar a necessidade como o vir-a-ser-necessário do encontro de contingentes. É assim que vemos não somente o mundo da vida (os biólogos atentaram para isto recentemente, especialmente os que devem ter conhecido Darwin), mas também o mundo da história, consolidar-se em certos momentos felizes na "pega" de elementos conjugados num encontro adequado para desenhar uma tal figura: uma tal espécie, um tal indivíduo, um tal povo. (ALTHUSSER, 2005, p. 29)

Portanto, é verdade que, em certo sentido, o destino da contingência é a necessidade, mas essa necessidade é histórica, o que significa que ela só é necessária por um certo período de tempo. Note-se, além do mais, que nenhum dos filósofos realistas se dá ao trabalho de examinar o conceito de história. Como pode o real ser a-histórico?

Para o materialista, existem indivíduos, existem elementos, existem formas, mas não existe um sujeito pré-constituído. 0 sujeito é o que só pode surgir quando as coisas desaparecem. Obviamente Brassier, como já vimos, ressalta a proximidade do real e do nada, mas não chega a dizer que esse nada é justamente o espaço de surgimento do sujeito. Se a realidade do real se assemelha com a ausência, com a sua nadificação, então estamos muito perto daquilo que Lacan, no seminário XVIII, D’un Discours qui ne serait pas du semblant (De um discurso que não fosse semblante) caracteriza como "desuniverso" (LACAN, 2009, p. 12). 0 "desuniverso", ou seja, o desaparecimento abismal das coisas produzido por seu próprio ser, é o que liberta a subjetividade falante. 0 sujeito é o resultado (e não a premissa) de uma desintegração do mundo. A contingência radical do real, que implica seu desaparecimento potencial, não conjura o sujeito, mas o faz aparecer. Sem dúvida, o sujeito da correlação é pensado como um "antes", 
um a priori, mas essa anterioridade não é nada mais do que a sombra desse sujeito que vem sempre depois, quando o penhasco do real desmoronou sobre si mesmo.

Althusser vê o prenúncio desse colapso e de sua consequência subjetiva na teoria rousseauísta do contrato social. Rousseau é, também, um pensador do nascimento residual do sujeito. De fato, o sujeito pega forma [prend forme, toma forma], somente quando as coisas desaparecem. Apresentada como uma penúria (chega um momento em que, no estado de natureza, as coisas não estão mais disponíveis em quantidade suficiente para satisfazer as necessidades dos indivíduos), a ausência das coisas marca o início da política e, nisso, o surgimento do sujeito. Que se torna, diz Althusser, parte de uma comunidade. No entanto, essa penúria, que está na origem do devir político, só é explicável pelo acaso.

É aqui, sem dúvida, que encontramos o mais profundo de Rousseau, descoberto e recoberto nesta visão sobre qualquer teoria possível da história, que pensa a contingência da necessidade como efeito da necessidade da contingência, par de conceitos desconcertantes, mas que é preciso, sem dúvida, considerar. (ALTHUSSER, 2005, p. 24)

A passagem do estado de natureza para o estado civil detalha a lógica acidental de uma nadificação do real (das coisas) que se torna uma necessidade depois do advento da comunidade 5 .

Mais uma vez, Rousseau mostrou claramente que o surgimento da política coincidiu com a desertificação da terra, provocada pelo dedo de Deus, isto é, por nada, sem origem nem razão, o que abre a possibilidade do simbólico: ou seja, do sentido, do conceito e do pensamento. Por isso, o conceito de universal só pode emergir do desuniverso.

Althusser continua com sua leitura de $O$ Príncipe, de Maquiavel. Ser realista é acreditar na fortuna. Ser materialista é acreditar que a fortuna é uma força. A força da fortuna é a "virtude (virtù)". A forma do desuniverso, ou seja, a forma política, emergirá do encontro entre a fortuna - ou seja, a contingência - e a força: a aliança entre a raposa e o leão. Desta junção, o príncipe não é o autor, mas o teatro, governado como é - no seu interior - pelo seu corpo - a matéria de seu ser -, pelos próprios elementos que ele governa.

\footnotetext{
5 “É no vazio político que se deve [neste momento] realizar o encontro" (ALTHUSSER, 2005, p. 14).
} 
Desta forma, o Príncipe é governado do seu interior pelas variações deste outro encontro aleatório: o da raposa, de um lado, e do leão e do homem, por outro. Este encontro pode não acontecer, mas pode também acontecer. Ele deve ainda ser durável para que a figura do Príncipe "pegue" no povo, ou seja, "pegue" forma. (ALTHUSSER, 2005, p. 14)

O sujeito residual encontra a sua mais alta expressão na definição que Althusser dá do Príncipe. O Príncipe de Maquiavel, ele afirma, é "um homem do nada", "saído do nada, e partindo de um lugar indefinido" (ALTHUSSER, 2005, p. 13). Este lugar inatribuível é a ausência do real. “Os dados são assim lançados na mesa de jogo, ela mesma vazia" (ALTHUSSER, 2005, p. 24).

Compreende-se que o real não é somente a relação das coisas entre si, das coisas em si mesmas, fora de qualquer síntese subjetiva. 0 real também proporciona, ao se retirar, esse espaço vazio no qual o sujeito pega forma [prend forme, toma forma].

\section{O post-realismo é uma anarquia?}

É óbvio que esse texto de Althusser engaja o materialismo em uma direção que não é mais marxista. Seria abusivo dizer que esta direção prefigura um devir anarquista? Jacques Rancière define precisamente como "anárquico" o vazio que preside a comunidade política, uma comunidade que "não é carregada por nenhuma necessidade histórica e não traz nenhuma. Está entregue apenas à constância de seus próprios atos" (RANCIÈRE, 2014, p. 122). A própria natureza se divide, explica Rancière, o real se cinde e o movimento de retirada das coisas deixa esse vazio em que se inicia o processo de uma subjetivação. Ora, “toda subjetivação política é a manifestação de um afastamento [...] uma desidentificação, o arrancar à naturalidade de um lugar, a abertura de um espaço do sujeito onde qualquer um pode contar-se, porque é o espaço de uma contagem dos incontados, do relacionamento entre uma parte e de uma ausência de parte" (RANCIÈRE, 1996, p. 48).

De minha parte, chamo de anarquista, e não simplesmente anárquico, a retirada contingente do real do qual o sujeito emerge. 0 materialismo se torna anarquista quando não precisa mais de um "príncipe", ou seja, de uma arché, para pensar sua contingência originária.

Nenhum filósofo contemporâneo se interessou de perto pelo pensamento de Proudhon. No entanto, o que Proudhon chama pela primeira vez, em um sentido positivo, de "anarquia" é 
a organização (e não, como de costume se acredita, a desorganização) da sociedade por si mesma, sem este "princípio de autoridade" que sugere que um príncipe ou um governo sejam necessários para a transformação da contingência em uma ordem política. Como Elisée Reclus afirma: "A anarquia é a ordem sem o poder", ou seja, é antes de mais nada a desconstituição teórica e prática do "preconceito governamental”. Um preconceito que, claro, è também aquele de Rousseau. Em Résistance à la révolution, Proudhon afirma:

A constituição externa do poder coletivo, à qual os gregos deram o nome de arché, principado, autoridade, governo, se baseia, portanto, nesta hipótese: que um povo, que o ser coletivo que chamamos de sociedade, não pode governar-se, pensar, agir, exprimir-se, por si mesmo. De maneira análoga [acontece] aos seres dotados de personalidade individual, que necessitam, por essa razão, ser representados por um ou mais indivíduos, os quais, a qualquer título, serão considerados os depositários da vontade do povo e seus agentes. Segundo esta hipótese, é impossível que o poder coletivo, que pertence essencialmente à massa, se exprima e atue diretamente, sem o intermediário de órgãos expressamente constituídos e, por assim dizer, investidos ad hoc. Parece, se dirá - e isso explica a constituição do Estado em todas as suas variações e espécies - que o ser coletivo, que a sociedade, sendo apenas um ente de razão, não possa tornar-se sensível senão pela encarnação monárquica, aristocrática usurpação ou mandato democrático. Consequentemente, qualquer manifestação própria e pessoal lhe será interditada. (PROUDHON, 2013, p. 368-369)

O problema do materialismo, tal como Althusser o transforma, é que o mesmo permanece ligado, podemos dizer correlacionado, ao privilégio de um sujeito dominante. Privilégio de um príncipe, e, mais uma vez, de um princípio ou de um arconte. 0 vazio como espaço da política não pode ser o lugar do Uno. 0 anarquismo é a única forma política possível de decorrelação. Hoje, deve ser pensada a ligação entre a ausência de uma arché, a irredutibilidade do real e o caráter residual da subjetividade.

0 "realismo" contemporâneo não surgiu em um momento qualquer e não deve, portanto, se contentar com a neutralidade política que, até o momento, tem sistematicamente demonstrado. É importante perceber que está surgindo, ao mesmo tempo, uma tomada de consciência planetária que se manifesta de forma cada vez mais visível através do despertar da iniciativa coletiva, da experimentação autónoma e do surgimento de novas coerências sociais em todo o mundo. 0 realismo se inscreve no ponto de reviravolta anarquista do materialismo contemporâneo. 
Não existe o real sem sujeito. Mas se trata, desta forma, de compreender plenamente o que significa "o sujeito do real". 0 sujeito do real não existe antes do real, mas provém dele. 0 sujeito é o a posteriori do real. Como Slavoj Žižek escreve no decorrer da sua leitura crítica de Après la finitude (Depois da finitude), “o verdadeiro fóssil é o próprio sujeito na impossibilidade de seu estatuto objetal - o fóssil sou eu, como o gato apavorado que me vê. Isto é o que realmente foge à correlação, não o em si ou o objeto, mas o sujeito como objeto, [isto é, como objeto impossível]" (ŽIŽEK, 2012, p. 64).

Será definido, portanto, político a prova simbólica do encontro dos sujeitos abandonados pelo real e tornado possível somente graças ao vazio deixado pela retirada do próprio real. 0 materialismo descreve seja a pega de forma [prise de forme, tomada da forma] contingente de agregados atômicos na natureza, seja a incorporação de sujeitos no espaço vazio do ser e, ao mesmo tempo, a relação entro os dois. Por esta razão, o materialismo, com efeito, compreende o realismo.

Sem levar em conta os efeitos do sujeito no real, sem levar em conta o sujeito concebido como "eco do real", o realismo corre o risco de ser uma simples apologia da contemplação das "coisas, isto é, enfim, uma forma particular de passividade ontológica. Certamente não devemos esquecer a lição de Marx, segundo a qual por trás das coisas estão 'os processos que elas escondem"' (MERLEAU-PONTY, 1955, p. 56).

Despedir-se do sujeito sem outra forma de processo, é amputar o real de suas revoluções. A contingência radical implica não apenas que a ordem física possa ser modificada a todo momento, mas também que a ordem social nunca é estabelecida de uma vez por todas. É importante pensar, medir a margem, estreitíssima, mas decisiva, que separa a modificação física da transformação histórica.

Althusser já havia circunscrito essa tarefa em sua radicalidade ao escrever que o novo materialismo está "forçado a pensar dentro de um horizonte esfacelado entre o aleatório do Encontro e a necessidade da Revolução" (ALTHUSSER, 2005, p. 24). Mas esse horizonte, ainda dependente demais de um sujeito, ou de um modelo governamental, hoje se metamorfoseia em outro tipo de unidade dilacerada, aquela dos sujeitos sem senhores, [sem nenhuma autoridade]. 


\section{Referências}

ALTHUSSER, L. "A corrente subterrânea do materialismo do encontro". Trad. M. G. Zoppi Fontana. Crítica Marxista, n. 20, Rio de Janeiro: Ed. Revan, 2005, p. 9-48.

BRASSIER, “Concepts and Objects”. In: The Speculative Turn: Continental Realism and Materialism. Melbourne: Re-Press, 2011, p. 47-65.

BRASSIER, R. Alien theory: The Decline of Materialism in the Name of Matter. PhD thesis, University of Warwick, 2001.

BRASSIER, R. Le Néant déchaîné : lumières et extinction. Trad. fr. A. Daures, Paris: PUF, 2017.

HARMAN, G. "The Future of Continental Realism. Heidegger's Fourfold". Chiasma Issue, 3, 28 de outubro 2018, pp. 81-98.

HARMAN, G. Bells and Whistles, More Speculative Realism. Winchester-Washington: Zero Books, 2013.

LACAN, J. Seminário, livro 18- De um discurso que não fosse semblante. Trad. V. Ribeiro, Rio de Janeiro: Jorge Zahar Ed., 2009.

MEILLASSOUX, Q. Après la Finitude, Essai sur la contingence radicale. Paris: Seuil, 2004.

MERLEAU-PONTY, M. Les Aventures de la dialectique. Paris: Gallimard, coll. "Folio", 1955.

MERLEAU-PONTY, M. As Aventuras da Dialética. Trad. C. Berliner, 1a․ ed., São Paulo: Martins Fontes, 2006.

MILLER, J.-A. "La suture (Éléments de la logique du signifant)". Cahiers pour l'analyse, n. 1 \& 2, 1966, pp. 36-51.

PROUDHON, P.-J. Actes de la révolution : Résistance : Idée de la révolution. Paris : Hachette, 2013.

RANCIÈRE, J. 0 desentendimento: política e filosofia. Trad. A. Leite Lopes, São Paulo: Ed. 34, 1996.

RANCIÈRE, J. 0 ódio à democracia. Trad. M. Echalar. São Paulo: Boitempo, 2014.

ŽIŽEK, S. Less than Nothing. Hegel and the Shadow of Dialectical Materialism. Londres: Verso, 2012.

ŽIŽEK, S. Menos que nada. Hegel à sombra do materialism dialético. Trad. R. Bettoni. São Paulo: Boitempo, 2013.

Recebido em: 20/11/2021

Aprovado em: 21/12/2021

\section{Catherine Malabou}

É professora de filosofia do Centre for Research in Modern European Philosophy (CRMEP) da Universidade de Kingston em Londres. Em 2016, na Universidade da Califórnia em Irvine, ela ocupou a cátedra de Literatura Comparada e Línguas e Estudos Europeus, anteriormente atribuída a Jacques Derrida. Sua pesquisa vai da neurociência à filosofia da política, da psicanálise ao feminismo. No centro de sua filosofia está o conceito de plasticidade, que ela atribui a Georg Wilhelm Friedrich Hegel, e o conceito científico de neuroplasticidade. Entre suas obras principais estão: L'Avenir de Hegel: Plasticité, Temporalité, Dialectique (1996), La Plasticité au soir de l'écriture (2004), Que faire de notre cerveau? (2004), Les Nouveaux Blessés: de Freud a la neurologie: penser les traumatismes contemporains (2007), Changer de différence: Le féminin et la question philosophique (2009), Avant demain. Épigenèse et rationalité (2014, Avant demain. Épigénèse et rationalité (2014), 
0 vazio político do realismo contemporâneo, ou da anarquia que virá DOI: $10.20873 / \mathrm{rpv} 6 \mathrm{n} 2-25$

Métamorphoses de l'intelligence (2017). Le Plaisir effacé. Clitoris et pensé (2020) e em língua portuguesa: Ontologia do acidente: ensaio sobre a plasticidade destrutiva (2014). 